guidelines. The majority of children screened did not have a BBI. This data highlights that we do not know the incidence of BBI in LAC. Larger data sets would be needed to investigate this further to determine the incidence and help guide our screening practice.

\section{G287(P) CHILDREN'S FEARS OF THE HOSPITAL ENVIRONMENT AND THE EFFECTIVENESS OF TEDDY BEAR HOSPITAL}

${ }^{1} \mathrm{~N}$ Punjabi, ${ }^{1} \mathrm{~S}$ Shahid, ${ }^{1} \mathrm{M}$ Dwaraknath, ${ }^{1} \mathrm{H}$ Khalid, ${ }^{1} \mathrm{~N}$ Sahdev, ${ }^{1} \mathrm{~K}$ Punjabi, ${ }^{2} \mathrm{U}$ Khalid, ${ }^{1}$ P Sedgwick, ${ }^{1,3}$ A Gour. ${ }^{1}$ St George's, University of London, St George's University Hospitals NHS FT, London, UK; ${ }^{2} U C L$, London, UK; ${ }^{3}$ Paediatric Intensive Care Unit, St George's University Hospitals NHS FT, London, UK

\subsection{6/archdischild-2020-rcpch.249}

${ }^{4}$ Medical Statistics and Medical Education, Institute for Medical and Biomedical Education

Aims Children attending hospital have fears and concerns, often due to a lack of familiarity with the medical environment. Medical students are often unconfident when interacting with children. Poor communication can adversely affect patient care and patient experience.

Teddy Bear Hospital (TBH) is an international scheme where medical students run interactive clinics teaching healthcare topics at local schools in south London. There is currently limited research on its effectiveness. This study aims to evaluate the effect of $\mathrm{TBH}$ on:

- Children's knowledge and anxiety regarding the medical environment in hospitals

- Medical students' confidence in interacting with children

Methods This prospective study was conducted over six months in 2018. Three questionnaires (designed with input from a Clinical Child Psychologist) were completed:

- Knowledge before and after clinic

- Matched Likert scales for 'worry' before and after clinic

- Volunteer questionnaire after clinic

The McNemar-Bowker test of symmetry was used to test for change in the children's subjective feelings.

Results 153 children were encountered at 4 interactive clinics. Knowledge of all topics tested increased after the TBH clinic. Fewer children felt 'worried'/'very worried' after the clinic in all topics with the most significant decrease noted in going to the hospital $(83.6 \%, \mathrm{P}<0.05)$ (table 1). All volunteers had increased confidence in interacting with children.

Conclusion TBH reduces children's fears while increasing their knowledge of the hospital medical environment and improving

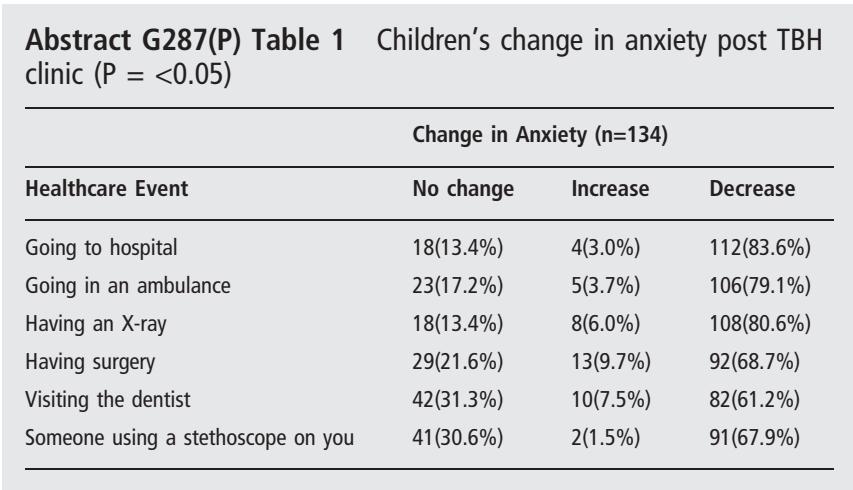

medical students' confidence in interacting with children. Adding a TBH clinic to the medical school curriculum may be a worthwhile consideration.

\section{G288(P) ABSTRACT WITHDRAWN}

\section{G289(P) PARENTAL EVALUATION OF A COMMUNITY PAEDIATRIC CLINIC FOR CHILDREN AND YOUNG PEOPLE WITH DEVELOPMENTAL DIFFICULTIES FOLLOWING ADOPTION AND SPECIAL GUARDIANSHIP ORDER}

H Towse, B Cooper. Southwark Community Paediatric Services, Guy's and St Thomas' NHS FT, London, UK

\subsection{6/archdischild-2020-rcpch.250}

Aims There is growing appreciation of the evolving difficulties for children placed in adoptive/special guardianship order (SGO) families, and the need for specialist input. Previous local service review identified $7 / 51$ children adopted with no initial developmental difficulties recognised who were subsequently re-referred to community paediatrics. Consequently, an innovative service was established to enable review by a consultant with expertise in adoption and looked after children. This evaluation aimed to examine parental perspectives on the value of this service.

Methods 27 parent/guardian questionnaires were posted following clinic review and initial actions. Parents were asked to report on a 5-point scale ('strongly agreed' to 'strongly disagreed') if being reviewed in the clinic: a) helped their child, b) benefited from seeing a professional with adoption expertise, or c) offered opportunities to discuss concerns. Free text responses were also encouraged to ascertain what was helpful, and suggestions for improvement. 12 families were additionally asked to complete PedsQL and SDQ forms.

Results A high proportion of questionnaires 16 (59\%) were returned. Of these, $13(81 \%)$ agreed/strongly agreed the clinic had helped their child. 13 (81\%) agreed/strongly agreed their child benefitted from review with a professional with expertise in adoption. $16(100 \%)$ agreed/strongly agreed that they, as parents, benefitted from discussing concerns with an adoption professional.

14 questionnaires had additional comments, thematic analysis of which revealed that parents largely appreciated the consultation style and professional understanding of the different complex aspects of their child's life. Suggestions for improvement included: direct liaison with school, and the ability to have direct consultant contact.

Conclusion This evaluation demonstrated positive parental experience from this innovative clinic for children and young people following adoption/SGO. This value is especially important given the unmet need in this group around unidentified developmental difficulties, the complexity/heterogeneity of these issues, and the need for improved information gathering. These findings will be used to advocate for increased resources locally and may provide evidence for other services to offer a similar pathway. 